The path of the shadow defined by these numbers differs sensibly from that given in NATURE, vol. xv. p. 65. It passes to the north of Nimrud instead of the south.

VVith the permission of Mr. Hind, I also transmit the following list of solar eclipses, computed by him, of which the results are preserved in the manuscripts of the Royal Observatory :-

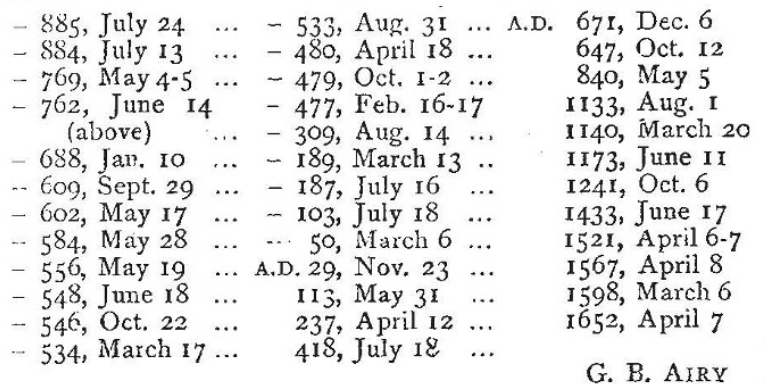

Royal Observatory, Greenwich, December 5

\section{Negretti's Reversible Thermometer and the Arctic Expedition}

CAPT. NARES presents his compliments to the editor of NATURE, and requests him to correct a mistake which Capt. Nares inadvertently made in his official report to the Admiralty concerning the late Arctic expedition, and which has been reprinted in NaTURE.

In obtaining some deep-sea temperatures, which proved the existence of a sub-stratum of water warmer than that at the sur face, the instruments used were the reversible thermometers of Negretii and Zambra, not Casella's. The Casella thermometer was used on other occasions, but not at the time referred to.

II. M.S. Alert, Portsmouth, November 30

\section{The Arctic Expedition}

Two or three considerations have led me to believe that possibly the recent Arctic Expedition has not been so fortunate as might have been wished, and that the same amount of foresight, courage, and energy, expended on a similar expedition another year might be attended with much more satisfactory results.

The considerations referred to are these :-

Tifty years ago Sir Edward Parry traversed a distance of some bundreds of miles in sledges upon what he at first supposed to be the main pack; but on finding that as fast as he travelled northwards he uas drifting to the south, he concluded what he had mis:aken for the main pack, was after all only a loose floe of immonse extent.

Now in 1872 , on the return of the American expedition, we were all given to understand that an open Polar Sea existed where instead is now found a sea of ancient ice. All testimony concurred in pointing to this open sea. The climate was warmer than further south; birds were seen flying north; a creeping herbage flourished, and bright flowers were not absent. Musk oxen, rabbits, and lemmings also abounded. Now these Polaris explorers were neither mendacious nor stupid; and it seems to me that it is rather premature to set down their inference from all they observed as a mistake.

Now, sir, my theory, true or false, new or old, is this:- This Palieocrystic Sea is really a vast floating island of ice ; say 500 miles in oiameter. Just like the ice in a pail or on a pond, it $m \in l i s$ in the hot weather at the edges, and then, disengaged from the land, it floats hither or thither, according to the direction of the prevalent winds or currents. If this theory be correct, it accounts for Parry's disappointing journey, for the inferences based on the Polaris observations, and for the otherwise unaccountable fact that the ice encountered by the recent explorers is undoubtediy ancient. The fact that the vast floe showed no signs of drifting a ay last summer only shows that the wind was unfavourable, or that this northernmost Greenland coast, when once the ice is stranded, does not easily relinquish its grasp. Possibly if a Hecla had attempted in 1876 what was impracticable in 1827, or if an Alert had tried in 1827 what has just proved a failure, both enterprises would have succeeded.
Next time two opposite routes must be undertaken simul taneously, of which one will fail and the other succeed.

17, Porchester Terrace, W.

WORDSWORTH DONNISTHORPE

\section{The Age of the Rocks of Charnwood Forest}

IN reference to the letters which have appeared in NATURE (vol. xv. p. 97) allow me to say, in the first place, that I neither attached, nor intended to attach, any discredt to Mr. Woodward's very useful manual for the statements it contains in reference to the age of the Charnwood Forest Rocks. On the other hand, $\mathrm{I}$ am gratified to find that so competent an objerver as the Rev. T. G. Bonney concurs with me in the view "that there is not a particle of evidence for their Laurentian age." This was the special point of my letter; and I fail to see that Prof. Green's hypothetical inferences from certain sections at Markfield (of which he fears that he has kept no record) are of much value in the question. Prof. Green, however, admits that the great mass of these rocks give no evidence of Laurentian age.

As regards what may be the respective limits of "Cambrian" and "Silurian" rocks that is another question. I am quite aware that Sedgwick claimed formations as "Cambrian" which are not so recognised by the Geological Survey, nor by the majority of authors, continental as well as British ; for example, M. Barrande. To which of the series of formations belonging to the Cambrian system of Sedgwick the forest rocks are to be referred I am not prepared to say; but I think it must be allowed that the negative evidence founded on the absence of fossils ought to have some weight in favour of the view that they are referable to the horizon of the "Cambrians" of the Geological Survey rather than to that of the Llandeilo or Caradoc beds.

Mr. Bonney's comparison of the forest rocks with those of the volcanic series of the Lake District is very suggestive; nor is the correspondence of the strike of the beds in both districts without its weight, where every circumstance ought to be taken into consideration in question of such uncertainty. It would also be very desirable if some general understanding could be arrived at regarding the respective limits of the Cambrian and Silurian systems. There are scarcely two authors who adopt the same view on this subject. Theoretically it may be a matter of small consequence; but practically it gives rise to confusion amongst geologists and amongst students of geology. As this is the age of "conferences" why should not a conference of Palæozoic geologists meet and lay down a frontier line for the two kingdoms, which would last, perhaps, for a generation, and until the "instinct of nationality" crops up and brings on another conflict between the inhabitants of Cambria and Siluria, and their allies respectively?

Geological Survey Office, Dublin, December 4

\section{"Towering" of Grouse, Partridges, \&c.}

Most of your readers doubtless know what is meant by the towering of game-birds; but, for the sake of those who do not, I will begin by describing the facts. When a partridge, for instance, is hit while on the wing by a few pellets of shot-perhaps only by one or two-the flight may continue for a variable distance; but, if the bird is a "towerer," a slight irregularity soon begins to show itself, after which the flight rapidly becomes more and more laboured, till eventually the bird ceases its onward motion altogether. The direction of the flight now changes from the horizontal to the perpendicular, and with a rapid fluttering sort of action the bird rises to a variable height, when all motion suddenly ceases, the animal falls like a stone, and the sportsman then knows that when he finds his partridge it will be lying dead on the exact spot where he "marlied it down."

Before proceeding to state the cause of these curious movements, I should like to draw more prominent attention to the facts, first, that the time after receiving the wound during which horizontal flight continues is variable; second, that the limits of variation are tolerably definite, a bira never towering until it has flown some distance after being shot, and never flying any very great distance before towering; and third, that the height to which the bird rises is also variable, this height being sometimes only $I$ or 2 feet, and at other times 40 or 50 . 